\title{
Consumo e Digestibilidade de Subprodutos do Processamento de Frutas em Ovinos ${ }^{1}$
}

\section{José Edilton Lousada Junior ${ }^{2}$, José Neuman Miranda Neiva ${ }^{3}$, Norberto Mário Rodriguez ${ }^{4}$, José Carlos Machado Pimentel ${ }^{5}$, Raimundo Nonato Braga Lôbo ${ }^{6}$}

\begin{abstract}
RESUMO - Esta pesquisa foi realizada objetivando-se avaliar o valor nutritivo de subprodutos do processamento de frutas. Foram estudados subprodutos de abacaxi, acerola, goiaba, maracujá e melão, utilizando-se 20 ovinos machos castrados, com peso médio de 34,5 kg. Adotou-se o delineamento experimental inteiramente casualizado, com cinco tratamentos (subprodutos) e quatro repetições. Os consumos de matéria seca (CMS) dos subprodutos de goiaba, maracujá e melão foram semelhantes, porém superiores ao CMS do subproduto de acerola. Os maiores consumos de proteína bruta (CPB) foram observados com maracujá e melão (g/animal/dia, g/UTM), enquanto acerola apresentou menor CPB. O subproduto de goiaba apresentou maior consumo de fibra em detergente neutro (CFDN) e fibra em detergente ácido (CFDA)e o de maracujá, maior coeficiente de digestibilidade aparente da matéria seca (DMS). Os subprodutos de acerola e goiaba apresentaram DMS inferior aos demais. Os coeficientes de digestibilidade aparente da proteína bruta dos subprodutos de maracujá e melão foram superiores aos demais subprodutos. Quanto aos coeficientes de digestibilidade da fibra em detergente neutro (DFDN) e da fibra em detergente ácido (DFDA), os subprodutos de acerola e goiaba mostraram-se inferiores, enquanto o subproduto de maracujá apresentou DFDA e DFDN superiores aos demais subprodutos. Não foram observadas diferenças para o balanço de nitrogênio entre os subprodutos estudados. Os resultados comprovaram que os subprodutos de abacaxi, maracujá e melão podem ser utilizados na alimentação de ruminantes, enquanto os subprodutos de acerola e goiaba apresentaram baixos coeficientes de digestibilidade, limitando sua utilização para ruminantes.
\end{abstract}

Palavras-chave: consumo, digestibilidade, ovinos, subprodutos

\section{Intake and Dry Matter Digestibility of By-products of Fruit Processer in Sheep}

ABSTRACT - This work was carried out aiming to evaluate the nutritive value of byproducts of fruit processor. Byproducts of pineapple, west indian cherry (WIC), guava, passion fruit and melon were evaluated. Twenty sheep castrated males, with average weight of $34.5 \mathrm{~kg}$, were assigned to a completely randomized design with five treatments (byproducts) and four replications. Dry matter intakes (DMI) of byproducts of guava, passion fruit and melon by the animals were similar but higher than WIC byproduct. The highest crude protein intake (CPI) (g/animal/day, g/BW 0.75 ) was observed in passion fruit and melon byproducts, while WIC byproduct the lowest CPI. Guava byproduct showed the higher intakes of neutral detergent fiber (NDF) and acid detergent fiber (ADF) and passion fruit byproduct showed the highest apparent digestibility of dry matter (ADDM) coefficient. Guava and WIC byproducts showed ADMS lower than the others. The coefficients of apparent digestibility of crude protein (ADCP) of passion fruit and melon byproducts were higher than the others byproducts. As for, the coefficients of apparent digestibility of NDF (ADNDF) and ADF (ADADF), WIC and guava byproducts were lower while passion fruit byproduct showed ADNDF and ADADF higher than the others. No difference among evaluates byproducts for nitrogen balance was observed. Results showed that; pineapple, passion fruit and melon byproducts could be used in ruminant diets. However, WIC and guava byproducts showed low nutrient digestibility coefficients, restricting their use in ruminant diets.

Key Words: byproducts, digestibility, intake, sheep

\section{Introdução}

O Nordeste brasileiro é uma região onde as condições climáticas adversas prejudicam o desenvolvimento das atividades na agropecuária, gerando carências, principalmente nutricionais, que acometem parte de sua população. A situação se estende aos rebanhos criados, cuja baixa produtividade se deve aos manejos alimentar, sanitário e reprodutivo deficientes.

Na região Nordeste, vem se desenvolvendo um importante setor da agropecuária, a fruticultura. Nos últimos anos, tem-se observado, de maneira geral, um

\footnotetext{
${ }^{1}$ Pesquisa Financiada pela FUNCAP, pelo CNPq e pela CAPES/PROCAD, parte da dissertação apresentada pelo primeiro autor para obtenção do título de Mestre em Zootecnia, pela Universidade Federal do Ceará.

2 Agrônomo, bolsista da FUNCAP (edilton.jr@bol.com.br).

3 Professor da Universidade Federal do Tocantins (araguaia@uft.edu.br).

${ }^{4}$ Professor da Escola de Veterinária da UFMG (norberto@vet.ufmg.br). Bolsista do CNPq.

5 Pesquisador da EMBRAPA-Agroindústria Tropical (machado@cnpat.embrapa.br).

${ }^{6}$ Pesquisador da EMBRAPA-Caprinos (lobo@cnpc.embrapa.br). Bolsista do CNPq.
} 
processo de profissionalização, caracterizado pela exploração de áreas mais extensas, pela utilização da irrigação e pelo incremento de novas tecnologias, visando a elevada e qualitativa produção de frutos. Em resposta a esse avanço, o número de agroindústrias instaladas por toda a região tem aumentado significativamente, gerando incremento na produção de resíduos agroindustriais não-utilizáveis na alimentação humana, que podem ser aproveitados na dieta animal, tornando-se importante fator de barateamento nos custos de produção.

Atualmente, a produção de frutas destina-se a atender à demanda por frutas frescas, no entanto, existe uma tendência mundial para o mercado de produtos transformados, como conservas, sucos, geléias e doces. Entretanto, segundo dados da FAO, citados por Bartholo (1994), nos países em desenvolvimento, como é o caso do Brasil, as perdas póscolheita de frutas frescas são estimadas em torno de 20 a 50\%. Em geral, calcula-se também que, do total de frutas processadas, sejam gerados, na produção de sucos e polpas, $40 \%$ de resíduos agroindustriais para as frutas manga, acerola, maracujá e caju. Constantemente, as agroindústrias investem no aumento da capacidade de processamento, gerando grandes quantidades de subprodutos, que, em muitos casos, são considerados custo operacional para as empresas ou fonte de contaminação ambiental.

A região Nordeste tem grande importância no cultivo da maioria das espécies frutíferas tropicais, especialmente abacaxi, abacate, banana, caju, coco, mamão, manga, maracujá, uva, acerola e goiaba. O abacaxi (safra 2000) e o melão (safra 1998) responderam por $38 \%$ da produção nacional (ANUÁRIO, 2000), enquanto acerola, goiaba, manga, mamão, maracujá, caju (pseudofruto) e banana obtiveram 69,6; 19,$8 ; 49,71 ; 52,4 ; 44 ; 96,5$ e $37,4 \%$, respectivamente, da produção nacional (IBGE, 1996).

Apesar da posição de destaque do Nordeste ocupa na produção frutícola nacional, foi a produção animal que mais contribuiu para o crescimento na renda da agropecuária $(7,9 \%)$ na região Nordeste, cujo PIB cresceu de $2,3 \%$ para $3,1 \%$ em 1996 , em relação ao ano anterior (IBGE, 1996). No entanto, estudos demonstram que, no setor de produção de carne ovina e caprina, ainda existe demanda insuficiente, em virtude da baixa qualidade e da sazonalidade de oferta desses produtos.
Estratégias para a melhoria do rebanho nordestino, caracterizado por baixos níveis produtivos, seriam o manejo alimentar adequado, principalmente nas épocas secas do ano, e o uso de sistemas intensivos de exploração, como o confinamento ou semiconfinamento, tornando-se necessário contar com alimentos de bom valor nutritivo e de baixo custo.

Surge, então, a necessidade de se estudar a viabilidade de inclusão de diversas fontes alimentares alternativas e quantificar as respostas animais em termos produtivos e econômicos. Uma das alternativas é a introdução dos subprodutos agroindustriais na dieta dos animais; porém, a maioria desses alimentos ainda não foi estudada, desconhecendo-se sua composição e seus níveis adequados de utilização econômica e biológica na produção animal.

Este estudo foi desenvolvido com o objetivo de avaliar o valor nutritivo de subprodutos da indústria processadora de frutas, tendo em vista seu uso como fonte alimentar alternativa para suprir as necessidades do rebanho, melhorando, assim, a eficiência do manejo alimentar.

\section{Material e Métodos}

O trabalho foi conduzido no Núcleo de Pesquisas em Forragicultura do Departamento de Zootecnia do Centro de Ciências Agrárias da Universidade Federal do Ceará (UFC), no município de Fortaleza-CE, situado na zona litorânea, a 15,49m de altitude, $3^{\circ} 43^{\prime} 02^{\prime \prime}$, de latitude sul, e $38^{\circ} 32^{\prime} 35^{\prime \prime}$ de longitude oeste. O clima de Fortaleza, segundo Köeppen, é do tipo AW'- Tropical chuvoso.

Foram estudados os subprodutos da extração de sucos e polpas (abacaxi, acerola, goiaba, maracujá e melão), devidamente desidratados, até que atingissem teor de umidade entre 13 e $16 \%$. A desidratação dos subprodutos foi feita ao sol e em área cimentada, sendo espalhados em camadas de, aproximadamente, $7 \mathrm{~cm}$ de espessura e revolvidos pelo menos três vezes ao dia. O subproduto de abacaxi era composto por cascas e polpa prensada; o de acerola, basicamente por sementes, com baixa porcentagem de frutos refugos; o de goiaba, por sementes e polpa macerada; e os subprodutos de maracujá e melão eram compostos por cascas e sementes. Os dados referentes às composições química e bromatológica dos subprodutos estão apresentados na Tabela 1.

Foram utilizados 20 ovinos SRD deslanados machos, castrados, com idade de 9 a 11 meses e peso 
médio de $34,5 \mathrm{~kg}$, em delineamento inteiramente casualizado, com cinco tratamentos (abacaxi, acerola, goiaba, maracujá e melão) e quatro repetições, com um animal por unidade experimental. Os animais foram mantidos em gaiolas de estudos metabólicos individuais, equipadas com coletores e separadores de fezes e urina, além de cochos, para fornecimento do alimento e da mistura mineral, e bebedouros com água permanentemente à disposição.

As fezes e a urina foram coletadas, pesadas e medidas duas vezes ao dia, às $7 \mathrm{~h}$ e às $17 \mathrm{~h}$. Para as fezes, foram retiradas amostras de aproximadamente $10 \%$ do total de cada coleta, posteriormente acondicio- nadas em sacos plásticos, identificadas e mantidas em congelador a $-10^{\circ} \mathrm{C}$. Ao final do ensaio, após a homogeneização, uma alíquota de $300 \mathrm{~g}$ referente a cada animal foi retirada para posteriores análises. Para urina, foram retiradas amostras de aproximadamente $10 \%$ do material, que foram filtradas em algodão e acondicionadas em vidros de cor escura com tampas devidamente identificadas. Foram adicionados nas vasilhas coletoras de urina, $100 \mathrm{~mL}$ de ácido clorídrico 1:1, evitando que houvesse perdas de nitrogênio por volatilização. Ao final do período de coleta, as amostras correspondentes a cada animal foram descongeladas, homogeneizadas e filtradas novamen-

Tabela 1 - Teores médios de matéria seca (MS), matéria orgânica (MO), proteína bruta (PB), fibra em detergente neutro (FDN), fibra em detergente ácido (FDA), celulose (CEL), hemicelulose (HEM), lignina (LIG), extrato etéreo (EE), cinzas, nitrogênio insolúvel em detergente ácido (NIDA) e nitrogênio insolúvel em detergente neutro (NIDN) dos subprodutos de abacaxi, acerola, goiaba, maracujá e melão

Table 1 - Average levels of dry matter (DM), organic matter (OM), crude protein $C P$ ), neutral detergent fiber (NDF), acid detergent fiber (ADF), cellulose (CEL), hemicellulose (HEM), lignin (LIG), ethereal extract $(E E)$, ashes $(A S H)$, acid detergent insoluble nitrogen (ADIN) and Neutral detergent insoluble nitrogen (NDIN) of pineapple, west indian cherry, guava, passion fruit and melon by products

\begin{tabular}{|c|c|c|c|c|c|}
\hline \multirow[t]{2}{*}{$\begin{array}{l}\text { Nutrientes } \\
\text { Nutrients }\end{array}$} & \multicolumn{5}{|c|}{$\begin{array}{l}\text { Subprodutos } \\
\text { By-products }\end{array}$} \\
\hline & $\begin{array}{l}\text { Abacaxi } \\
\text { Pineapple }\end{array}$ & $\begin{array}{c}\text { Acerola } \\
\text { West indian } \\
\text { cherry }\end{array}$ & $\begin{array}{l}\text { Goiaba } \\
\text { Guava }\end{array}$ & $\begin{array}{c}\text { Maracujá } \\
\text { Passion fruit }\end{array}$ & $\begin{array}{l}\text { Melão } \\
\text { Melon }\end{array}$ \\
\hline $\begin{array}{l}\text { MS (\%) } \\
D M\end{array}$ & 84,7 & 85,1 & 86,3 & 83,3 & 84,6 \\
\hline $\begin{array}{l}\mathrm{MO}^{1} \\
\mathrm{OM}\end{array}$ & 93,2 & 97,3 & 96,6 & 90,2 & 85,4 \\
\hline $\begin{array}{l}\mathrm{PB} \\
C P^{1}\end{array}$ & 8,4 & 10,5 & 8,5 & 12,4 & 17,3 \\
\hline $\begin{array}{l}\text { FDN } \\
N D F^{l}\end{array}$ & 71,4 & 71,9 & 73,5 & 56,2 & 59,1 \\
\hline $\begin{array}{l}\mathrm{FDA}^{1} \\
A D F\end{array}$ & 30,7 & 54,7 & 54,7 & 49,0 & 49,2 \\
\hline $\begin{array}{l}\text { CEL } \\
C E L^{1}\end{array}$ & 25,9 & 35,1 & 37,2 & 39,3 & 32,6 \\
\hline $\begin{array}{l}\text { HEM } \\
H E M^{1}\end{array}$ & 40,7 & 17,2 & 18,8 & 10,3 & 9,9 \\
\hline $\begin{array}{l}\mathrm{LIG} \\
L I G^{1}\end{array}$ & 5,3 & 20,1 & 18,5 & 9,5 & 16,6 \\
\hline $\begin{array}{l}\mathrm{EE} \\
E E^{1}\end{array}$ & 1,2 & 3,2 & 6,0 & 1,0 & 3,3 \\
\hline $\begin{array}{l}\text { CINZAS } \\
\text { Ash }^{1}\end{array}$ & 6,8 & 2,7 & 3,4 & 9,8 & 14,6 \\
\hline $\begin{array}{l}\text { NIDA }^{2} \\
\text { ADIN }\end{array}$ & 16,3 & 26,5 & 21,0 & 20,0 & 14,8 \\
\hline $\begin{array}{l}\mathrm{NIDN}^{2} \\
\text { NDIN }\end{array}$ & 38,4 & 39,3 & 35,2 & 24,6 & 27,3 \\
\hline
\end{tabular}

\footnotetext{
${ }^{1}$ Porcentagem da matéria seca.

1 Percentual of dry matter.

2 Porcentagem do nitrogênio total.

${ }^{2}$ Total nitrogen percentual.
} 
te em gaze, retirando-se uma alíquota de $100 \mathrm{~mL}$ para posteriores análises.

Os subprodutos foram oferecidos como alimento exclusivo aos animais e em quantidade que permitisse sobras de, aproximadamente, 15\%. Antes do fornecimento, os subprodutos foram triturados em moinho tipo martelo dotado de peneira de $0,5 \mathrm{~cm}$ de diâmetro.

O ensaio teve duração de 21 dias, dos quais 14 dias foram para adaptação dos animais às dietas e ao ambiente experimental e sete, para determinação do consumo, da digestibilidade aparente dos nutrientes e do balanço de nitrogênio.

Nas amostras do alimento fornecido, das sobras e das fezes, foram determinados os teores de matéria seca (MS), proteína bruta (PB), extrato etéreo (EE), fibra em detergente neutro (FDN), fibra em detergente ácido (FDA) e cinzas, enquanto, nas amostras de urina, determinou-se o nitrogênio total. As análises foram realizadas no laboratório de Nutrição Animal do Departamento de Zootecnia da Universidade Federal do Ceará, segundo Silva (1990).

No Laboratório de Nutrição Animal do Departamento de Zootecnia da Escola de Veterinária da Universidade Federal de Minas Gerais (UFMG), foram realizadas, nos alimentos fornecidos, as análises de nitrogênio insolúvel em detergente neutro (NIDN), nitrogênio insolúvel em detergente ácido (NIDA) e lignina, conforme Licitra et al. (1996).

Foram avaliados os consumos de matéria seca (CMS) e de matéria orgânica (CMO), de proteína bruta $(\mathrm{CPB})$, de fibra em detergente neutro (CFDN) e de fibra em detergente ácido (CFDA), além da digestibilidade da matéria seca (DMS), da proteína bruta (DPB), da fibra em detergente neutro (DFDN), da fibra em detergente ácido (DFDA) e da matéria orgânica (DMO), o teor de nutrientes digestíveis totais (NDT) e o balanço de nitrogênio (BN). Para o cálculo do NDT, utilizou-se a equação NDT $=$ PB Digestível + 2,25 x EE Digestível + Carboidratos Totais digestíveis, utilizada pelo Sistema de Cornell (Sniffen et al., 1992).

Os dados foram analisados por meio de análise de variância, verificando-se, anteriormente, se atendiam às pressuposições necessárias para realização da análise. Para todas as características, foi utilizado o teste Tukey, para comparação das médias dos tratamentos, por intermédio do programa SAS (SAS, 1990).

\section{Resultados e Discussão}

O consumo de matéria seca (CMS) do subproduto de goiaba, em g/animal/dia, \% PV e g/UTM, foi superior $(\mathrm{P}<0,01)$ ao dos subprodutos de abacaxi e acerola, porém, não diferiu $(\mathrm{P}>0,05)$ do $\mathrm{CMS}$ dos subprodutos de maracujá e melão, que foram semelhantes $(\mathrm{P}>0,05)$ ao do abacaxi (Tabela 2$)$.

$\mathrm{O}$ menor CMS foi observado nos animais alimentados com o subproduto da acerola, provavelmente em virtude do elevado teor de lignina $(20,1 \%)$, uma vez que este subproduto é composto basicamente de sementes, material naturalmente lignificado. Entretanto, apesar de o subproduto de goiaba possuir teores de FDN e lignina próximos aos do subproduto da acerola, os animais alimentados com o subproduto de goiaba apresentaram o maior CMS, o que ser decorrente da presença de elevada porcentagem de sementes, as quais possuem alta densidade específica, aumentando a taxa de passagem da digesta pelo trato gastrintestinal e reduzindo a digestibilidade dos nutrientes, porém permitindo maior consumo em razão do rápido esvaziamento ruminal.

Trabalhando com silagens de capim-elefante contendo subproduto do caju (bagaço da extração de suco) em ovinos, Ferreira (2002) obteve consumo médio de 3.38,2 g/animal/dia.

Os CMS médios dos animais alimentados com os subprodutos testados, expressos em \% PV, variaram de 1,4\% (acerola) a 4,4 \% PV (goiaba). Vieira et al. (1999) alimentaram novilhos com farelo de casca de maracujá e observaram CMS médio de 3,3\% PV pelos animais, enquanto Siqueira et al. (1999), utilizando subproduto de maracujá ensilado na terminação de bovinos de corte, verificaram ingestão diária de matéria seca de $2,03 \%$ do peso vivo.

Os valores de CMS, em g/UTM, dos subprodutos estudados variaram de 34,2 (acerola) a 106,8 g/UTM (goiaba). De acordo com o NRC (1985), a exigência nutricional de mantença de ovinos adultos é de 53,2 g/UTM, valor alcançado pelos subprodutos de abacaxi (65,0 g/UTM), goiaba (106,8 g/UTM), maracujá (84,0 g/UTM) e melão (83,3 g/UTM), sendo ainda os três últimos superiores ao valor padrão (feno de alfafa), que é de $80 \mathrm{~g} / \mathrm{UTM}$, segundo Crampton (1957).

Os consumos médios de proteína bruta (CPB) dos animais alimentados com os subprodutos estudados estão apresentados na Tabela 3. Os animais alimen- 
Tabela 2 - Consumo de matéria seca (CMS) dos subprodutos do abacaxi, acerola, goiaba, maracujá e melão

Table 2 - Dry matter intake (IMD) of pineapple, west indian cherry, guava, passion fruit and melon by-products

\begin{tabular}{|c|c|c|c|}
\hline \multirow[t]{2}{*}{$\begin{array}{l}\text { Subproduto } \\
\text { By-product }\end{array}$} & \multicolumn{3}{|c|}{$\begin{array}{l}\text { CMS } \\
I M D\end{array}$} \\
\hline & $\begin{array}{l}\text { g/ animal/ dia } \\
\text { g/animal/day }\end{array}$ & $\begin{array}{c}\% \mathrm{PV} \% \\
B W\end{array}$ & $\begin{array}{l}\text { g/UTM } \\
g / B W .75\end{array}$ \\
\hline $\begin{array}{l}\text { Acerola } \\
\text { West indian cherry }\end{array}$ & $500,3 \mathrm{c}$ & $1,4 \mathrm{c}$ & $34,2 \mathrm{c}$ \\
\hline $\begin{array}{l}\text { Goiaba } \\
\text { Guava }\end{array}$ & $1527,4 a$ & $4,4 \mathrm{a}$ & $106,8 \mathrm{a}$ \\
\hline $\begin{array}{l}\text { Maracujá } \\
\text { Passion fruit }\end{array}$ & $1200,9 \mathrm{ab}$ & $3,5 \mathrm{ab}$ & $84,0 \mathrm{ab}$ \\
\hline $\begin{array}{l}\text { Melão } \\
\text { Melon }\end{array}$ & $1157,5 \mathrm{ab}$ & $3,5 \mathrm{ab}$ & $83,3 \mathrm{ab}$ \\
\hline CV & 2,2 & 12,0 & 3,1 \\
\hline
\end{tabular}

Médias seguidas de letras diferentes, na mesma coluna, diferem entre si $(P<0,01)$, pelo teste de Tukey. Means followed by differents letters, in same column, differ $(P<.01)$ by Tukey test.

Tabela 3 - Consumo de proteína bruta (CPB) dos subprodutos de abacaxi, acerola, goiaba, maracujá e melão

Table 3 - Crude protein intake (CPI) of pineapple, west indian cherry, guava, passion fruit and melon by-products

\begin{tabular}{lccc}
\hline $\begin{array}{l}\text { Subproduto } \\
\text { By-product }\end{array}$ & \multicolumn{3}{c}{ CMS } \\
& \multicolumn{3}{c}{ IMD } \\
\cline { 2 - 4 } & $\begin{array}{c}\text { g/ animal/ dia } \\
\text { g/animal/day }\end{array}$ & $\begin{array}{c}\text { PPV } \\
B W\end{array}$ & $\begin{array}{c}\mathrm{g} / \mathrm{UTM} \\
\mathrm{g} / B W^{0.75}\end{array}$ \\
\hline $\begin{array}{l}\text { Abacaxi } \\
\text { Pineapple }\end{array}$ & $75,3 \mathrm{c}$ & $0,22 \mathrm{c}$ & $5,3 \mathrm{c}$ \\
$\begin{array}{l}\text { Acerola } \\
\text { West indian cherry }\end{array}$ & $55,5 \mathrm{c}$ & $0,16 \mathrm{~d}$ & $3,8 \mathrm{~d}$ \\
$\begin{array}{l}\text { Goiaba } \\
\text { Guava }\end{array}$ & $129,7 \mathrm{~b}$ & $0,37 \mathrm{~b}$ & $9,1 \mathrm{~b}$ \\
$\begin{array}{l}\text { Maracujá } \\
\text { Passion fruit }\end{array}$ & $148,4 \mathrm{ab}$ & $0,43 \mathrm{~b}$ & $10,4 \mathrm{ab}$ \\
$\begin{array}{l}\text { Melão } \\
\text { Melon } \\
\text { CV }\end{array}$ & $193,7 \mathrm{a}$ & $0,58 \mathrm{a}$ & $13,9 \mathrm{a}$ \\
\hline
\end{tabular}

Médias seguidas de letras distintas na mesma coluna diferem entre si $(\mathrm{P}<0,01)$, pelo teste Tukey. Means followed by differents letters, in same column, differ $(P<.01)$ by Tukey test.

tados com o subproduto de melão apresentaram CPB superior $(\mathrm{P}<0,01)$ àqueles alimentados com $\mathrm{O}$ subproduto do abacaxi, acerola e goiaba, porém não diferenciaram dos CPB apresentados pelos animais alimentados com o subproduto de maracujá. Os animais que receberam subprodutos de abacaxi e de acerola apresentaram menores $\mathrm{CPB}(\mathrm{P}<0,01)$, porém não diferiram entre si $(\mathrm{P}>0,05)$. Os maiores $\mathrm{CPB}$ observados nos animais que consumiram subprodutos de melão e maracujá são resultantes dos maiores CMS (Tabela 2) e, possivelmente, dos mais elevados teores de PB (Tabela 1).

Vale ressaltar que, segundo o NRC (1985), o CPB necessário para que ovinos de $20 \mathrm{~kg}$ e $30 \mathrm{~kg}$ atinjam ganho de peso de $250 \mathrm{~g} /$ dia é de $168 \mathrm{~g} /$ dia. Portanto, somente o subproduto de melão, se fornecido como alimento exclusivo, supre estas exigências, enquanto o subproduto de maracujá atende a $88,4 \%$ dos requerimentos.

Para os CPB expressos em \%PV, observou-se que os maiores consumos foram obtidos com os 
animais alimentados com subproduto de melão $(\mathrm{P}<0,01)$. O subproduto de acerola foi consumido em menor percentual $(\mathrm{P}<0,01)$ que os demais subprodutos.

Os maiores CPB expressos em g/UTM foram registrados quando os animais foram alimentados com os subprodutos de maracujá e melão $(\mathrm{P}<0,01)$, os quais não diferiram $(\mathrm{P}>0,05)$ entre si. O subproduto da acerola foi o menos consumido $(\mathrm{P}<0,01)$. Os resultados obtidos sugerem que os subprodutos do processamento do melão suprem as exigências protéicas, mesmo de categorias de animais mais exigentes. Ressalta-se que, de modo geral, os níveis de $\mathrm{CPB}$ foram bons, se comparados àqueles verificados em ovinos alimentados com silagem de capim-elefante com $75 \%$ de subproduto de maracujá fresco (Reis et al., 2000). Esse fato é justificado pelo maior teor e consumo de matéria seca e pelos teores de PB mais elevados de alguns subprodutos em relação às silagens.

Os consumos de fibra em detergente neutro (CFDN) expressos em g/animal/dia, \% PV e g/UTM estão apresentados na Tabela 4. O CFDN dos animais alimentados com subproduto de goiaba foi superior $(\mathrm{P}<0,01)$ aos demais. O maior $\mathrm{CFDN}$ observado em animais alimentados com subproduto de goiaba, em relação àqueles que consumiram maracujá e melão, é decorrente do maior teor de FDN, uma que apresentaram CMS semelhantes $(\mathrm{P}>0,05)$. O maior consumo de FDN observado nos animais alimentados com o subproduto de goiaba foi basicamente em função do
CMS desse subproduto ter sido 65\% maior que o CMS dos animais alimentados com subproduto do abacaxi (Tabela 2).

Moreira et al. (2001) forneceram para ovinos silagem de milho e feno de alfafa e observaram CFDN de 447,9 e 702,9 g/animal/dia, respectivamente. Estes resultados mostram que os subprodutos testados, com exceção do subproduto da acerola, foram consumidos em quantidades que permitem caracterizá-los como volumosos de boa qualidade.

Com relação ao CFDN em \%PV e g/UTM, houve variações de 1,0 a 3,3 \%PV e 24,0 a 78,8 g/UTM. Reis et al. (2000) forneceram silagem de capimelefante com $50 \%$ de subproduto do maracujá para ovinos e obtiveram CFDN de 42,9 g/UTM. O NRC (2001) considera, para bovinos leiteiros, limite de consumo de 1,4\% de FDN em relação ao peso vivo. Embora possuam semelhança quanto à origem (processamento de frutas), os subprodutos apresentaram grande variação no CFDN, que podem ser atribuídas à natureza da fibra, evidenciando que o conceito preconizado pelo NRC (2001), considerando-se apenas o teor de FDN, não pode ser aplicado para os subprodutos estudados. Nota-se, então, que as variações no CFDN dos subprodutos trabalhados parecem ser influenciadas pelas proporções de cada componente da parede celular, as quais podem alterar a digestibilidade e, conseqüentemente, afetar o consumo deste nutriente.

Tabela 4 - Consumo de fibra em detergente neutro (CFDN) dos subprodutos de abacaxi, acerola, goiaba, maracujá e melão

Table 4 - $\quad$ Neutral detergent fiber intake (NDFI) of pineapple, west indian cherry, guava, passion fruit and melon by-products

\begin{tabular}{lccc}
\hline $\begin{array}{l}\text { Subproduto } \\
\text { By-product }\end{array}$ & \multicolumn{3}{c}{ CFDN } \\
& \multicolumn{3}{c}{ NDFI } \\
\cline { 2 - 4 } & $\begin{array}{c}\text { g/ animal/ dia } \\
\text { g/animal/day }\end{array}$ & $\begin{array}{c}\text { PPV } \\
\text { Abacaxi }\end{array}$ & $2,0 \mathrm{~b} / \mathrm{bTM}$ \\
$\begin{array}{l}\text { Pineapple } \\
\text { Acerola }\end{array}$ & $670,6 \mathrm{~b}$ & $47,2 \mathrm{~b}$ \\
$\begin{array}{l}\text { West indian cherry } \\
\text { Goiaba }\end{array}$ & $351,1 \mathrm{c}$ & $1,0 \mathrm{c}$ & $24,0 \mathrm{c}$ \\
$\begin{array}{l}\text { Guava } \\
\text { Maracujá }\end{array}$ & $1126,4^{\mathrm{a}}$ & $3,3^{\mathrm{a}}$ & $78,8^{\mathrm{a}}$ \\
$\begin{array}{l}\text { Passion fruit } \\
\text { Melão }\end{array}$ & $706,5 \mathrm{~b}$ & $2,0 \mathrm{~b}$ & $49,4 \mathrm{~b}$ \\
$\begin{array}{l}\text { Melon } \\
\text { CV }\end{array}$ & $697,5 \mathrm{~b}$ & $2,1 \mathrm{~b}$ & $50,2 \mathrm{~b}$ \\
\hline
\end{tabular}

Médias seguidas de letras distintas na mesma coluna diferem entre si $(P<0,01)$, pelo teste Tukey. Means followed by differents letters, in same column, differ $(P<.01)$ by Tukey test. 
Os dados relativos aos consumos médios de fibra em detergente ácido (CFDA) obtidos com os subprodutos estudados encontram-se na Tabela 5. O CFDA observado nos animais alimentados com subproduto de goiaba foi superior $(\mathrm{P}<0,01)$ aos demais, ao passo que animais que consumiram subprodutos de maracujá e melão apresentaram CFDA semelhantes $(\mathrm{P}>0,05)$, porém superiores $(\mathrm{P}<0,01)$ aos obtidos com subprodutos de abacaxi e acerola.

O maior CFDA obtido com o subproduto de goiaba é atribuído ao maior CMS, pois, mesmo possuindo CMS semelhante aos subprodutos de maracujá e melão, apresenta maior valor absoluto.

Para os subprodutos testados, não houve relação entre o teor de lignina e o consumo de FDA. Observou-se que os menores teores de lignina dos subprodutos de abacaxi $(5,3 \%)$ e maracujá $(9,6 \%)$ não refletiram em CFDA mais elevados. Da mesma forma, verificou-se que o subproduto que proporcionou o maior CFDA (goiaba) possui elevado teor de lignina $(18,5 \%)$. Assim, as diferenças no CFDA podem estar associadas às variações na constituição dos subprodutos, pois nutrientes semelhantes podem apresentar diferenças na composição e no valor nutritivo.

Ferreira et al. (2002) mediram o consumo voluntário de silagens de capim-elefante com subprodutos da indústria de suco de caju em ovinos e observaram CFDA de 128,2 a 205,5 g/animal/dia.
Com relação ao CFDA, em \%PV e g/UTM, obtidos com os subprodutos avaliados, houve variações de 0,7 a $2,4 \%$ PV e 18,1 a 58,9 g/UTM. Freitas et al. (2002b) avaliando silagens de cinco genótipos de milho, observaram CFDA entre 14,1 a $18,1 \mathrm{~g} / \mathrm{UTM}$.

Os coeficientes de digestibilidade da matéria seca (DMS), proteína bruta (DPB), fibra em detergente neutro (DFDN), fibra em detergente ácido (DFDA), matéria orgânica (DMO) e os teores de nutrientes digestíveis totais (NDT) estão apresentados na Tabela 6.

O subproduto de maracujá apresentou DMS superior $(\mathrm{P}<0,01)$ aos demais, enquanto os de acerola e goiaba apresentaram as menores DMS $(\mathrm{P}<0,01)$, não diferindo $(\mathrm{P}<0,05)$ entre si.

A maior DMS do subproduto de maracujá pode ser atribuída ao baixo teor de lignina $(9,5 \%)$ associado ao bom teor de PB $(12,4 \%)$ em relação aos demais subprodutos. O teor de lignina do abacaxi $(5,3 \%)$ foi inferior ao subproduto de melão $(16,6 \%)$ (Tabela 1), no entanto, esses subprodutos apresentaram DMS semelhantes $(\mathrm{P}>0,05)$. Possivelmente, os teores mais elevados de PB, encontrados no subproduto de melão, $(17,3 \%)$ justifiquem a maior DMS do mesmo, pois, no caso do subproduto de abacaxi, o teor de PB foi de apenas $8,4 \%$, o que pode ter limitado a digestão dos nutrientes por deficiência de compostos nitrogenados para os microrganismos ruminais.

Tabela 5 - Consumo de fibra em detergente ácido (CFDA) dos subprodutos de abacaxi, acerola, goiaba, maracujá e melão

Table 5 - Acid detergent fiber intake (ADFI) of pineapple, west indian cherry, guava, passion fruit and melon by-products

\begin{tabular}{lccc}
\hline $\begin{array}{l}\text { Subproduto } \\
\text { By-product }\end{array}$ & \multicolumn{3}{c}{ CFDA } \\
& \multicolumn{3}{c}{ ADFI } \\
\cline { 2 - 4 } & $\begin{array}{c}\text { g/ animal/dia } \\
\text { g/animal/day }\end{array}$ & $\begin{array}{c}\% W \\
\mathrm{PV} \%\end{array}$ & $\begin{array}{c}\mathrm{g} / \mathrm{UTM} \\
\mathrm{g} / \mathrm{B} W^{.75}\end{array}$ \\
\hline $\begin{array}{l}\text { Abacaxi } \\
\text { Pineapple }\end{array}$ & $293,3 \mathrm{c}$ & $0,9 \mathrm{c}, 6 \mathrm{c}$ \\
$\begin{array}{l}\text { Acerola } \\
\text { West indian cherry }\end{array}$ & $265,0 \mathrm{c}$ & $0,7 \mathrm{c}$ & $18,1 \mathrm{c}$ \\
$\begin{array}{l}\text { Goiaba } \\
\text { Guava }\end{array}$ & $842,9 \mathrm{a}$ & $2,4^{\mathrm{a}}$ & $58,9 \mathrm{a}$ \\
$\begin{array}{l}\text { Maracujá } \\
\text { Passion fruit }\end{array}$ & $591,3 \mathrm{~b}$ & $1,7 \mathrm{~b}$ & $41,4 \mathrm{~b}$ \\
$\begin{array}{l}\text { Melão } \\
\text { Melon }\end{array}$ & $584,5 \mathrm{~b}$ & $1,8 \mathrm{~b}$ & $42,1 \mathrm{~b}$ \\
CV & 2,4 & 41,4 & 3,7 \\
\hline
\end{tabular}

Médias seguidas de letras distintas na mesma coluna diferem entre si $(P<0,01)$, pelo teste Tukey. Means followed by differents letters in same column differ $(P<.01)$ by Tukey test. 
Tabela 6 - Digestibilidade aparente da matéria seca (DMS), proteína bruta (DPB), fibra em detergente neutro (DFDN), fibra em detergente ácido (DFDA), matéria orgânica (DMO) e nutrientes digestíveis totais (NDT) dos subprodutos do abacaxi, acerola, goiaba, maracujá e melão

Table 6 - Dry matter aparent digestibility (DMAD), crude protein (CPAD), neutral detergent fiber (NDFAD), acid detergent fiber (ADFAD), organic matter (OMAD) and total digestive nutrient (TDN) of pineapple, west indian cherry, guava, passion fruit and melon by-products

\begin{tabular}{|c|c|c|c|c|c|c|}
\hline \multirow[t]{2}{*}{$\begin{array}{l}\text { Subproduto } \\
\text { By-product }\end{array}$} & \multicolumn{6}{|c|}{$\begin{array}{l}\text { Nutriente } \\
\text { Nutrient }\end{array}$} \\
\hline & $\begin{array}{c}\text { DMS } \\
D M A D\end{array}$ & $\begin{array}{l}\text { DPB } \\
C P A D\end{array}$ & $\begin{array}{l}\text { DFDN } \\
N D F A D\end{array}$ & $\begin{array}{l}\text { DFDA } \\
A D F A D\end{array}$ & $\begin{array}{l}\mathrm{DMO} \\
O M A D\end{array}$ & $\begin{array}{l}\text { NDT } \\
T D N\end{array}$ \\
\hline $\begin{array}{l}\text { Abacaxi } \\
\text { Pineapple }\end{array}$ & $47,5 b$ & $29,0 \mathrm{~b}$ & $50,8 \mathrm{a}$ & $51,0 \mathrm{~b}$ & $48,8 \mathrm{~b}$ & $45,6 \mathrm{~b}$ \\
\hline $\begin{array}{l}\text { Acerola } \\
\text { West indian } \\
\text { cherry }\end{array}$ & $22,8 \mathrm{c}$ & $33,2 b$ & $16,8 \mathrm{c}$ & $8,2 \mathrm{~d}$ & $30,1 \mathrm{c}$ & $32,2 \mathrm{~d}$ \\
\hline $\begin{array}{l}\text { Goiaba } \\
\text { Guava }\end{array}$ & $30,8 \mathrm{c}$ & $39,5 b$ & $17,7 \mathrm{c}$ & $13,0 \mathrm{~d}$ & $30,9 \mathrm{c}$ & $35,7 d$ \\
\hline $\begin{array}{l}\text { Maracujá } \\
\text { Passion fruit }\end{array}$ & $60,0 \mathrm{a}$ & $54,4 \mathrm{a}$ & $56,2 \mathrm{a}$ & $65,4^{\mathrm{a}}$ & $58,2 \mathrm{a}$ & $52,9^{\mathrm{a}}$ \\
\hline $\begin{array}{l}\text { Melão } \\
\text { Melon }\end{array}$ & $47,7 b$ & $64,8 \mathrm{a}$ & $38,7 \mathrm{~b}$ & $38,7 \mathrm{c}$ & $45,9 b$ & $42,0 \mathrm{c}$ \\
\hline CV & 9,5 & 13,7 & 11,8 & 11,2 & 7,9 & 7,7 \\
\hline
\end{tabular}

Médias seguidas de letras diferentes, na mesma coluna, diferem entre si $(P<0,01)$, pelo teste de Tukey. Means followed by different letters, in same column, differ $(P<.01)$ by Tukey test.

Os valores de DMS dos subprodutos estudados estão dentro da faixa de DMS obtida por outros autores que trabalharam com subprodutos do processamento de frutas e observaram valores de $28,4 \%$ a $78,2 \%$ (Hadjipanayiotou \& Louca, 1976; Müller, 1978; Rodrigues \& Peixoto, 1990a.; Reis et al., 2000).

Os subprodutos foram fornecidos de forma exclusiva para os animais e, portanto, é possível que tenha havido deficiência de alguns componentes dietéticos, como fibra efetiva, o que pode ter provocado elevação na taxa de passagem da digesta pelo trato gastrintestinal, reduzindo a digestibilidade dos nutrientes.

Os subprodutos de maracujá e melão apresentaram DPB semelhantes $(\mathrm{P}>0,05)$, porém superiores $(\mathrm{P}<0,01)$ às dos subprodutos de abacaxi, acerola $\mathrm{e}$ goiaba, que não diferiram entre si $(\mathrm{P}>0,05)$.

De modo geral, os valores de DPB são baixos em comparação aos altos teores de $\mathrm{PB}$ contidos nos subprodutos, porém, estão dentro da faixa de DPB obtida por outros autores que trabalharam com subprodutos desidratados do processamento de frutas(Göhl, 1973; Hadjipanayioton \& Louca, 1976; Müller, 1978; Dumont et al, 1985), os quais observaram valores entre $19,5 \%$ e $65,0 \%$.

Os subprodutos que apresentaram DPB mais elevada (maracujá e melão) são os que possuem maiores teores de proteína bruta (PB), de 12,4\% e 17,3\%, respectivamente, enquanto os subprodutos de abacaxi, acerola e goiaba, que possuem as menores DPB, apresentam teores de $\mathrm{PB}$ inferiores aos demais subprodutos, de 8,$4 ; 10,5$ e $8,5 \%$, respectivamente.

Segundo Van Soest (1994), os teores de NIDA dos alimentos interferem na DPB. Considerando-se os teores de NIDA (Tabela 1), verifica-se que, nem sempre, subprodutos com NIDA mais elevado apresentaram menor DPB. É o caso dos subprodutos de goiaba e maracujá, que possuem teores de NIDA semelhantes, de $21,0 \%$ e $20,0 \%$, respectivamente. Porém, o subproduto de maracujá apresenta DPB $(54,4 \%)$ superior ao de goiaba $(39,5 \%)$, em razão do maior teor de PB $(12,4 \%)$ em relação ao subproduto de goiaba $(8,5 \%)$. Percebe-se então que, para DPB dos subprodutos trabalhados, os teores de PB exerceram maior influência que os teores de NIDA.

Os subprodutos que apresentam alta porcentagem de sementes em sua constituição podem conter elevados teores de taninos, pois as sementes contêm maior concentração de taninos no tegumento. Van Soest (1994) cita subprodutos agroindustriais, como bagaço de tomate e subprodutos da uva, como alimentos ricos em tanino. Da mesma forma, Dumont et al. (1985), Reyne \& Garambois (1985) destacam a presença de tanino em subprodutos da industrialização da uva como fator responsável pela baixa digestibilidade 
aparente da proteína bruta (DPB), cujos valores foram de 12,9 e $13,0 \%$, respectivamente. Portanto, pode-se relacionar a presença de sementes, que possuem elevada quantidade de tanino, como um dos fatores responsáveis pela baixa digestibilidade da PB dos subprodutos de acerola e goiaba. Entretanto, os dados obtidos com o subproduto de abacaxi contrariam essa explicação, pois este subproduto não possui sementes e apresenta teores de NIDA, NIDN e lignina baixos, mas apresentou baixa DPB $(29,0 \%)$.

Para a DFDN, não se observou diferença $(\mathrm{P}>0,05)$ entre os subprodutos de abacaxi e maracujá, que foram superiores $(\mathrm{P}<0,01)$ aos demais. Os subprodutos de acerola e goiaba apresentaram a mais baixa $(\mathrm{P}<0,01)$ DFDN, não diferindo $(\mathrm{P}>0,05)$ entre si.

A digestibilidade da FDN pode ser influenciada pelos conteúdos dos componentes da parede celular, além da própria estrutura e forma de organização. Dessa forma, os valores mais elevados de DFDN foram obtidos com os subprodutos de abacaxi e maracujá, que apresentaram menores percentuais de lignina (5,3 e $9,5 \%$, respectivamente).

Embora o subproduto do melão tenha porcentagem de lignina $(16,6 \%)$ próxima à dos subprodutos de acerola $(20,1 \%)$ e goiaba $(18,5 \%)$, sua DFDN foi maior. Esse fato pode ser justificado pelo maior teor de PB no subproduto de melão, o que permite a criação de ambiente ruminal mais adequado aos microrganismos e, conseqüentemente, melhor digestão da fibra (FDN); ou, talvez, seja resultante das características específicas da parede celular do melão. Observou-se que as DFDN seguiram o mesmo comportamento dos valores de lignina presentes nos subprodutos. Os valores de DFDN obtidos por outros autores que trabalharam com subproduto de frutas variaram de 53,9 a 80,6\% (Müller, 1978; Rodrigues \& Peixoto, 1990a; Sing \& Narang, 1992, citados por Lavezzo, 1990; Reis et al., 2000).

O subproduto do maracujá apresentou DFDA superior $(\mathrm{P}<0,01)$ aos demais subprodutos, ao passo que os subprodutos de acerola e goiaba, as menores DFDA ( $\mathrm{P}<0,01)$, não diferindo $(\mathrm{P}>0,05)$ entre si. As variações na digestibilidade da FDA seguiram o mesmo comportamento do teor de lignina contido nesses alimentos, pois como a FDA é composta por celulose mais lignina, quanto maior o teor de lignina, menor a digestibilidade da FDA. Consequientemente, os subprodutos de goiaba e de acerola, que possuem maiores teores de lignina, 18,5 e $20,1 \%$ respectivamente, apresentaram menores DFDA.

Rodrigues \& Peixoto (1990a, 1990b) realizaram dois trabalhos com subproduto do abacaxi in natura e silagem do subproduto de abacaxi e obtiveram coeficientes de digestibilidade da FDA de 73,6 e $81,3 \%$, respectivamente. Sing \& Narang (1992), citados por Lavezzo, 1990, observaram, quando alimentaram bovinos com subproduto de maçã mais uréia, valor para DFDA de 48,7\%, semelhante ao subproduto de abacaxi $(51,0 \%)$.

Entre os subprodutos estudados, o de maracujá apresentou a maior $(\mathrm{P}<0,01)$ DMO. As médias de DMO dos subprodutos seguiram o mesmo comportamento da DMS. Rocha Jr. et al. (2002) verificaram alta correlação entre DMS e DMO quando analisaram o valor energético de vários alimentos para ruminantes. Dessa forma, a DMO traduz-se numa maneira eficiente de avaliação energética dos alimentos.

De modo geral, os subprodutos estudados possuem baixa DMO, porém os valores estão dentro da faixa obtida poroutros pesquisadores que trabalharam com subprodutos do processamento de frutas, que variaram de 28,0 a $83,0 \%$ (Göhl, 1973; Müller, 1978; Dumont \& Tisserand, 1978, citados por Lavezzo, 1990; Reyne \& Garambois, 1985; Dumont et al., 1985; Cerda et al., 1995).

O subproduto do maracujá apresentou o maior valor de $\mathrm{NDT}(\mathrm{P}<0,01)$. Numa faixa intermediária, situaram-se os subprodutos de abacaxi e de melão, que não diferiram entre $\mathrm{si}(\mathrm{P}>0,05)$. Os subprodutos de acerola e goiaba apresentaram NDT semelhantes $(\mathrm{P}>0,05)$, porém com valores inferiores $(\mathrm{P}<0,01)$ aos demais.

Outros autores que trabalharam com subprodutos do processamento de frutas observaram valores de NDT variando de 38,0 a 74,0\% (Vizcaino \& Smilg, 1971; Müller, 1978).

Os valores referentes ao balanço de nitrogênio (BN) (g/dia) dos subprodutos encontram-se na Tabela 7. Não se observou diferença $(P>0,05)$ entre os subprodutos estudados. O balanço de nitrogênio (BN) foi positivo para os subprodutos de abacaxi, goiaba, maracujá e melão, no entanto, o subproduto de acerola apresentou BN (g/dia) negativo, mostrando deficiência em nitrogênio para os animais.

Os subprodutos de goiaba, maracujá e melão permitiram consumo de nitrogênio mais elevado $(20,8 ; 23,7$ e 31,0 g/dia), além de maiores retenções, em termos absolutos. Segundo Silva \& Leão (1979), retenções de nitrogênio mais elevadas são conseqüência do melhor 
Tabela 7 - Balanço de nitrogênio em g/dia, nitrogênio ingerido, nitrogênio excretado nas fezes e nitrogênio excretado na urina

Table 7 - N Nitrogen balance in g/day(NB g/day), intake nitrogen (IN), fecal nitrogen (FN), urine nitrogen (UN)

\begin{tabular}{lcccc}
\hline $\begin{array}{l}\text { Subproduto } \\
\text { By-product }\end{array}$ & $\begin{array}{c}\text { Ningerido } \\
I N\end{array}$ & $\begin{array}{c}\text { N fecal } \\
F N\end{array}$ & $\begin{array}{c}\text { N urinário } \\
U M\end{array}$ & $\begin{array}{c}\text { BN (g/dia) } \\
\text { NB g/day }\end{array}$ \\
\hline $\begin{array}{l}\text { Abacaxi } \\
\begin{array}{l}\text { Pineapple } \\
\text { Acerola }\end{array}\end{array}$ & 12,0 & 8,5 & 2,1 & $1,4 \mathrm{a}$ \\
$\begin{array}{l}\text { West indian } \\
\text { cherry }\end{array}$ & 8,9 & 5,9 & 3,3 & $-0,3 \mathrm{a}$ \\
$\begin{array}{l}\text { Goiaba } \\
\text { Guava }\end{array}$ & 320,8 & 12,6 & 3,2 & $5,0 \mathrm{a}$ \\
$\begin{array}{l}\text { Maracujá } \\
\text { Passion fruit } \\
\begin{array}{l}\text { Melão } \\
\text { Melon }\end{array}\end{array}$ & 23,7 & 10,9 & 8,6 & $4,2 \mathrm{a}$ \\
\hline
\end{tabular}

Médias seguidas de letras diferentes, na mesma coluna, diferem entre si $(P<0,01)$, pelo teste Tukey. Means followed by different letters, in same column, differ $(P<.01)$ by Tukey test.

balanço energético-protéico característico de cada alimento, o que permite maior eficiência no aproveitamento da proteína, satisfazendo as necessidades protéicas dos animais.

Resultados semelhantes aos verificados nos subprodutos de goiaba, maracujá e melão foram relatados por Freitas et al. (2002a), ao avaliarem silagens de cinco genótipos de milho, e variaram de 4,4 a 5,7 g/dia. Martins et al. (2000) avaliaram silagens de genótipos de sorgo e encontraram para o tipo BR601 retenção de 4,8 g de nitrogênio/dia, enquanto Fonsêca Filho \& Leitão (1996) alimentaram ovinos com farelo dos pseudofrutos do cajueiro e observaram $\mathrm{BN}$ de 14,8 g/dia.

\section{Conclusões}

Os subprodutos de abacaxi, maracujá e melão caracterizaram-se por bom valor nutritivo, podendo ser utilizados na alimentação de ruminantes.

Existem limitações na utilização dos subprodutos de acerola e goiaba na alimentação de ruminantes, necessitando maiores estudos, como a utilização de tratamentos químicos ou físicos que visem melhorar o valor nutritivo destes subprodutos.

\section{Literatura Citada}

ANUÁRIO ESTATÍSCO DA AGRICULTURA BRASILEIRA - AgrianUAL 2000. São Paulo: FNP, M\&S Mendes \& Scotoni, 2000.

BÁRTHOLO, G.F. Perdas e qualidade preocupam. Informe Agropecuário, v.17, n.179, p.3, 1994.
CERDA, D.; MANTEROLA, H.; SIRHAN, L.A. et al. Estudio del uso de residuos agroindustriales en alimentación animal $\mathrm{x}$ Estudio de la disponibilidad y valor nutritivo de cinco cultivos hortícolas en la zona central de Chile. Avances en Producción Animal, v.20, p.191-209, 1995.

CRAMPTON, E.W. Interrelations between digestible nutrient and energy content, voluntary dry matter intake and the overall feeding value of forages. Journal of Animal Science, v.16, p.546-552, 1957.

DUMONT, R.; MESSAOUDI, L.; TISSERAND, J.L. Feeding value of dried or ensiled grape marc. Agriculture, v.13, p.277-281, 1985.

FERREIRA, A.C.H.; NEIVA, J.N.M.; RODRIGUEZ,N.M. et al. Consumo voluntário das silagens de capim elefante com diferentes níveis de subprodutos da indústria do suco de caju. In: REUNIÃO ANUAL DA SOCIEDADE BRASILEIRA DE ZOOTECNIA, 39., 2002, Recife. Anais... Recife: Sociedade Brasileira de Zootecnia, 2002. 1 CD.

FERREIRA, A.C.H. Valor Nutritivo das silagens de capimelefante com diferentes níveis de subprodutos da indústria do suco de caju. Fortaleza: Universidade Federal do Ceará, 2002. 101p. Dissertação (Mestrado em Zootecnia) Universidade Federal do Ceará, 2002.

FONSÊCA, V.M.; LEITÃO, S.C. Consumo voluntário e balanço do nitrogênio do farelo de resíduo industrial do pseudofruto do cajueiro (Anacardium occidentale L.). In: SIMPÓSIO NORDESTINO DE ALIMENTAÇÃO DE RUMINANTES, 1996, Natal. Anais... Natal: 1996. v.1.

FREITAS, G.A.R.; COELHO, C.G.; GONÇALVES, L.C. et al. Consumo e digestibilidade aparente da matéria seca, proteína e energia bruta, e balanço de nitrogênio das silagens de cinco genótipos de milho (Zea mays L.) em ovinos. In: REUNIÃO ANUAL DA SOCIEDADE BRASILEIRA DE ZOOTECNIA, 39., 2002, Recife. Anais... Recife: Sociedade Brasileira de Zootecnia, 2002a. 1 CD.a

FREITAS, G.A.R.; GONÇALVES, L.C.; COELHO, C.G. et al. Consumo e digestibilidade aparente das frações fibrosas das silagens de cinco genótipos de milho (Zea mays L.) em ovinos II. In: REUNIÃO ANUAL DA SOCIEDADE BRASILEIRA 
DE ZOOTECnIA, 39., 2002, Recife. Anais... Recife: Sociedade Brasileira de Zootecnia, 2002b. 1 CD

GÖHL, B.I. Citrus by-products for animal feed. World Animal Review, v.6, p.24-27, 1973.

HADJIPANAYIOTOU, M.; LOUCA, A. A note on the value of dried citrus pulp and grape marc as barley replacements in calf fattening diets. Animal Production, v.23, n.1, p.129-132, 1976.

INSTITUTO BRASILEIRO DE GEOGRAFIA E ESTATÍSTICA (IBGE). Censo Agropecuário, 1996. Disponível em: <http://www.ibge.gov.br/bda/Tabela/protabl.asp> Acesso em: $(15 / 08 / 2004)$.

LAVEZZO, O.E.N.M. Utilização de resíduos culturais e de beneficiamento na alimentação de bovinos. abacaxi, banana, caju, uva e maça. In: SIMPÓSIO SOBRE NUTRIÇÃO DE BOVINOS, 6., 1990, Piracicaba. Anais... Piracicaba: Fundação de Estudos Agrários Luiz de Queiroz, sd. p.7-46.

LICITRA, G.; HERNANDEZ, T.M.; Van SOEST, P.J. Standardization of procedures for nitrogen fractionation of ruminant feed. Animal Feed Science Technology, v.57, n.4, p.347-358, 1996.

MARTINS, R.G.R.; GONÇALVES, L.C.; RODRIGUES, J.A.S. et al. Consumo e digestibilidade aparente da matéria seca, proteína bruta e energia, e balanço de nitrogênio das silagens de quatro tipos de genótipos de sorgo (Sorghum bicolor(L.) Moench) em ovinos. In: REUNIÃO ANUAL DA SOCIEDADE BRASILEIRA DE ZOOTECNIA, 37., 2000, Viçosa, MG: Sociedade Brasileira de Zootecnia, 2000.

MOREIRA, A.L.; PEREIRA, O.G.; VALADARES FILHO, S.C. et al. Consumo e digestibilidade aparente dos nutrientes da silagem de milho e dos fenos de alfafa e de capim coastcross, em ovinos. Revista Brasileira de Zootecnia, v.30, n.3, p.1099-1105, 2001.

MÜLLER, Z.O. Feeding potential of pineapple waste for cattle. Word Animal Review, v.25, n.1, p.25-29, 1978.

NATIONAL RESEARCH COUNCIL - NRC. Nutrient requeriments of sheep. 6.ed. Washington, D.C.: National Academy of Science, 1985. 99p.

NATIONAL RESEARCH COUNCIL - NRC. Nutrient requeriments of dairy cattle. 7.ed. Washington, D.C.: NAS., 2001. 289p.

REIS, J.; PAIVA, P.C.A.; von TIESENHAUSEN, I.M.E.V. et al. Composição química, consumo voluntário e digestibilidade de silagens de resíduos do fruto de maracujá (Passiflora edulis Simsf. flavicarpa) e de capim-elefante (Pennisetum purpureum Schum) cv. Cameroon e suas combinações. Ciência e Agrotecnologia, v.24, n.1, p.213-224, 2000.

REYNE, Y., GARAMBOIS, X. Nutritive value of whole grape marc silage for sheep. Agriculture, Bul-013. p.233-290. Julho, 1985.
ROCHA JR., V.R.; VALADARES FILHO, S.C.; BORGES, A.M. et al. Determinação do valor energético de alimentos para ruminantes. In: REUNIÃO ANUAL DA SOCIEDADE BRASILEIRA DE ZOOTECNIA, 39., 2002, Recife. Anais... Recife: Sociedade Brasileira de Zootecnia, 2002. 1 CD.

RODRIGUES, R.C.; PEIXOTO, R.R. Composição bromatológica, digestibilidade e balanço de nitrogênio de resíduos da indústria de abacaxi. REUNIÃO ANUAL DA SOCIEDADE BRASILEIRA DE ZOOTECNIA, 27., 1990, Campinas/SP. Anais... Campinas: Sociedade Brasileira de Zootecnia, 1990a. p.92.

RODRIGUES, R.C.; PEIXOTO, R.R. Composição bromatológica, digestibilidade e balanço de nitrogênio de resíduos da indústria de abacaxi ensilado. In: REUNIÃO ANUAL DA SOCIEDADE BRASILEIRA DE ZOOTECNIA, 27., 1990, Campinas. Anais... Campinas: Sociedade Brasileira de Zootecnia, $1990 \mathrm{~b}$. p.93.

STATISTICAL ANALYSIS SYSTEM - SAS. User's guide. Cary: 1990.

SILVA, D.J. Análises de alimentos: métodos químicos e biológicos. Viçosa, MG: Universidade Federal de Viçosa, 1990. $165 \mathrm{p}$.

SILVA, J.F.C.; LEÃO, M.I. Fundamentos de nutrição dos ruminantes. Piracicaba: Livroceres, 1979. p.190-236.

SIQUEIRA, G.B.; ALCADE, C.R.; BERTIPAGLIA, L.M.A. et al. Utilização do resíduo de maracujá e silagens de híbridos de milho na terminação de bovinos de cortes em confinamento. Acta Scientiarum, v.21, n.3, p.749-753, 1999.

SNIFFEN, C.J.; O 'CONNOR, J.D.; Van SOEST, P.J. et al. A net carboidrate and protein system for evaluating cattle diets. II. Carboidrate and protein availability. Journal of Animal Science, v.70, n.11, p.3562-3577, 1992.

Van SOEST, P.J.; ROBERTSON, J.B.; LEWIS, B.A. et al. Methods for dietary fiber, neutral detergent fiber, and nonstarch polysaccharides in relation to animal nutrition. Journal of Dairy Science, v.74, n.10, p.3583-3597, 1991.

Van SOEST, P.J. Nutritional ecology of the ruminant. 2.ed. Ithaca: Cornell University Press, 1994. 476p.

VIEIRA, C.V.; VASQUES, H.M.; SILVA, J.F.C. Composição químico-bromatológica e degradabilidade in situ da matéria seca, proteína bruta e fibra em detergente neutro da casca do fruto de três variedades de maracujá (Passiflora spp). Revista Brasileira de Zootecnia, v.28, n.5, p.1148-1158, 1999.

VIZCAÍNO, E.S.; SMILG, N. Valor energético del subprodutos de uva em ovidos. Revista Nutrition Animal, v.9, n.3, p.153-166, 1971. 